\title{
Rapid Microbiological Assay for 5-Fluorocytosine
}

\author{
D. J. SCHIAVONE, M. D. PAGE, J. K. DAWBORN
}

British Medical fournal, 1973, 4, 380-382

\section{Summary}

A microbiological assay was developed for 5-fluorocytosine based on inhibition by the drug of the fall in $\mathrm{pH}$ produced by Candida albicans in a synthetic liquid culture medium. Serum and urine levels of the drug could be measured reproducibly in four hours.

\section{Introduction}

The increasing incidence of severe fungal infections resulting from the prolonged use of immunosuppressive and chemotherapeutic drugs has led to a parallel increase in the use of antifungal agents. One such agent, 5-fluorocytosine (5-FC), is an effective oral antifungal agent with few reported toxic side effects. However, there has been comparatively little experience with this drug which is excreted unchanged almost entirely by the kidney (Koechlin et al, 1966; Wade and Sudlow, 1972). Information about blood and urine 5-FC levels is particularly important when renal function is impaired or when high blood levels are required to achieve a therapeutic effect.

Satisfactory microbiological (Shadomy, 1969) and chemical (Wade and Sudlow, 1972) methods for the assay of 5-FC have been described, but these are not simple or quick. This paper describes a rapid and sensitive microbiological assay for 5-FC in blood and urine based on that of Faine and Knight (1968) for conventional antibiotics in which inhibition of acid production by a sensitive organism is used as a measure of drug concentration. Problems posed by the comparatively long generation time of Candida albicans and the use of a synthetic (suboptimal) medium to avoid neutralization of 5-FC by cytosine or peptones have been satisfactorily overcome.

\footnotetext{
Method

Preparation of Unknown and Standard Solutions.-A concentrated $(10,000 \mathrm{\mu g} / \mathrm{ml})$ solution of 5-FC (Roche Products Ltd.) in a mixture of 1 part of human serum to 7 parts of sheep serum was used as the stock solution. Working standards containing 1.0 to $20.0 \mu \mathrm{g} / \mathrm{ml} 5-\mathrm{FC}$ were made weekly bv diluting the stock solution with the same serum mixture. A 1 in 8 dilution of unknown test sera was made with sheep serum, so that standards and unknown samples contained the same concentrations of human and sheep serum. Urine was passed through a millipore filter and diluted $1: 100,1: 200$, and 1:400 with the same serum mixture. Diluted urine was then treated as for other samples. A $90-\mathrm{ml}$ sample of normal saline was added to $1.0 \mathrm{ml}$ of all standards, test sera, or con-

University of Melbourne, Austin Hospital, Heidelberg 3084, Victoria, Australia

D. J. SCHIAVONE, M.B. F R.C.P.A., Senior Lecturer in Medical Microbiology M. D. PAGE, M.SC., Graduate Research Assistant, Department of Microbiolog

J. K. DAWBORN, PH.D., F.R.A.C.P., Senior Renal Physician
}

trol sera which were then autoclaved at $5 \mathrm{lb} /$ in $^{2}\left(350 \mathrm{~g} / \mathrm{cm}^{2}\right)$ for 15 minutes. The turbidity resulting from protein denaturation does not interfere with the test.

Liquid Culture Medium.- The assay was carried out in a $3 \%$ glucose/yeast nitrogen broth (Difco 0392-15) medium. Stock medium could be stored satisfactorily at $4^{\circ} \mathrm{C}$ for many months and was made up as follows: glucose $30 \mathrm{~g}$, Difco YNB* $6.7 \mathrm{~g}$, L-asparagine $1.5 \mathrm{~g}$, distilled water to 1 litre.

Working glucose/YNB medium for assay was obtained by diluting the stock 1 in 8 with normal saline.

Preparation of Test Organism-A sensitive strain of $C$. albicans was harvested from nutrient agar and a heavy suspension made in normal saline. Aliquots were transferred to sterile ampoules and dried. Cultures from these ampoules were made as required on nutrient agar. Plates were held at $4^{\circ} \mathrm{C}$ for a month before being discarded. The evening before setting up an assay sufficient colonies were removed from the nutrient agar plate to make a suspension containing about 1 $\times 10^{6}$ organisms $/ \mathrm{ml}$ in $5 \mathrm{ml}$ of normal saline. A 2-ml sample of this suspension was added to $400 \mathrm{ml}$ of a $5 \%$ glucose/Difco nutrient broth in a 1-litre flask which was plugged with cotton-wool to allow escape of gas during incubation. After overnight incubation at $37^{\circ} \mathrm{C}$ on a shaker the number of organisms/ml were counted using a $1: 1,000$ dilution and a Neubauer counting chamber. Budding organisms were counted as two. Based on the bacterial count a measured volume of the overnight culture containing about $10^{10}$ candida was centrifuged. The supernatant was removed and the deposit of C. albicans suspended in $350 \mathrm{ml}$ of the working glucose/ YNB medium. A 4-ml sample of the suspension was mixed with $1 \mathrm{ml}$ of the diluted, autoclaved zero standard and adjusted by dropwise addition of a $\mathrm{pH} 7 \cdot 10$ Sorensons phosphate buffer to a final $\mathrm{pH}$ between 5.95 and 6.05. The amount of buffer required for the bulk suspension was calculated from this. The buffer was added and the volume made up to $400 \mathrm{ml}$ with medium. The final concentration of $C$. albicans in this suspension was about $2.5 \times 10^{7}$ organisms $/ \mathrm{ml}$.

Assay Procedure.-One $\mathrm{ml}$ of the diluted standard, control, or test sera and $4 \mathrm{ml}$ of the prepared candida suspension were mixed in a sterile McCartney bottle. All estimations were carried out in triplicate. Each assay included five control bottles without drug and six bottles containing $2 \mu \mathrm{g} / \mathrm{ml} \mathrm{5-FC}$ standard which were used to monitor the fall in $\mathrm{pH}$ of the medium during incubation. The $\mathrm{pH}$ of duplicate control samples was read immediately to establish the stanting $\mathrm{pH}$, which should be $6.00 \pm 0.05 \mathrm{pH}$ units. The remaining bottles were incubated at $37^{\circ} \mathrm{C}$ on a shaker until a pH of about 3.2 units was reached in the $2 \mu \mathrm{g} / \mathrm{ml}$ standard (usuallv about three and a half hours). The fall in $\mathrm{pH}$ in the $2 \mu \mathrm{g} / \mathrm{ml}$ monitor bottle was read in duplicate after incubation for $3 \mathrm{hr} 10$ $\min$ and $3 \mathrm{hr} 20 \mathrm{~min}$. At this time if the $\mathrm{pH}$ was 3.2 or less the metabolism of the organisms was stopped bv placing the bottles in crushed ice at $4^{\circ} \mathrm{C}$. If the $\mathrm{pH}$ remained above $3 \cdot 2$ further incubation was carried out until the appropriate fall in $\mathrm{pH}$ was achieved. Triplicate samples were pooled and mixed and the $\mathrm{pH}$ value read at $10^{\circ} \mathrm{C}$. A standard curve was constructed on linear or semi-log graph paper of $\mathrm{pH}$ versus drug concentration. The drug concentrations in the test samples were read directly from the standard curve.

*This medium contains $10 \mathrm{mg}$ histidine, $20 \mathrm{mg}$ methionine, and $20 \mathrm{mg}$ tryptophan per litre. 


\section{Results}

The growth of $C$. albicans produced a rapid fall in $\mathrm{pH}$ of the glucose/YNB medium over a period of four hours. This was dependent on the starting $\mathrm{pH}$, the initial concentration of $C$. albicans, and the rate of growth of the organism in the liquid culture medium. These factors therefore determine the sensitivity of the method. The effect of variation in the concentration of the organism on the rate of fall of $\mathrm{pH}$ in the liquid culture medium is shown in fig. 1 . A concentration of at least $10^{7}$ candida $/ \mathrm{ml}$ was necessary to produce a maximum fall of $\mathrm{pH}$ within four hours.

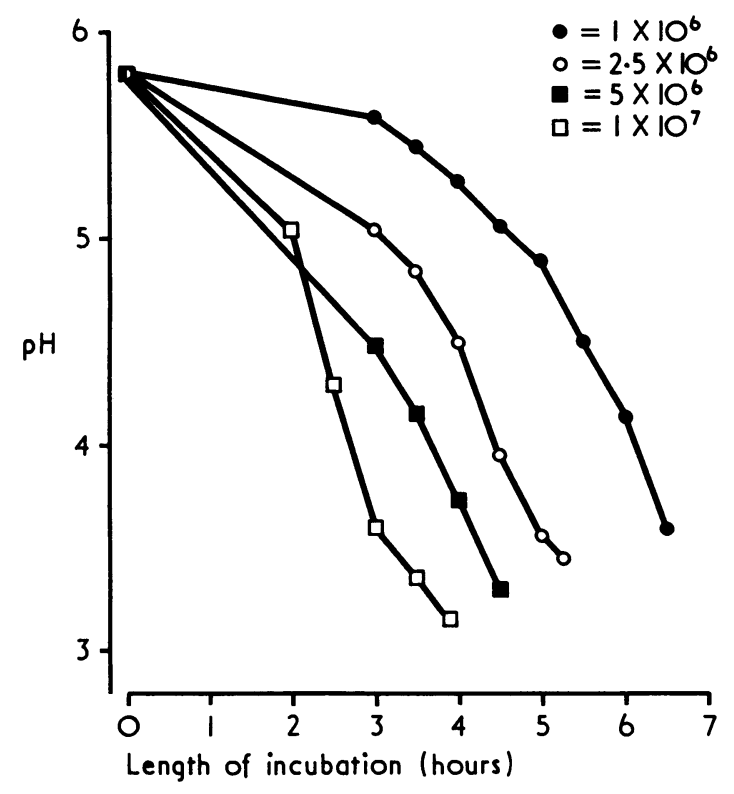

FIG. 1-Fall in pH in liquid culture medium incubated with concentrations of Candida albicans between $10^{6}$ and $10^{7}$ organisms $/ \mathrm{ml}$ showing a more rapid fall and steeper slope of $\mathrm{pH}$ curve with higher concentrations of organism.

The standard curve is based on the relation between drug concentration and the fall in $\mathrm{pH}$ for a fixed incubation time. The effect of variation in the starting $\mathrm{pH}$ on the slope of the

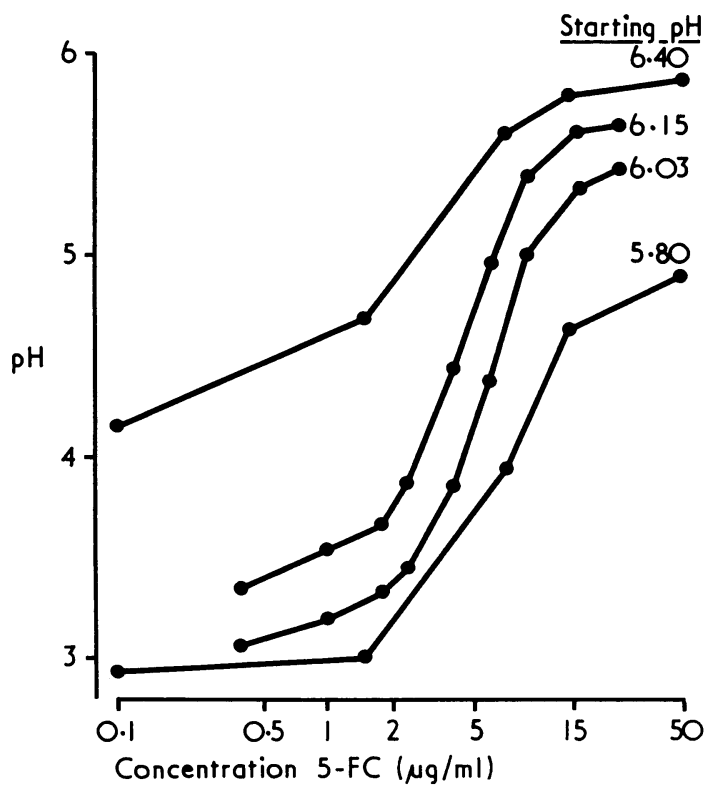

FIG. 2-Variation in slope of standard curve due to variation in initial $\mathrm{pH}$ of medium. Organism concentration $\left(2 \pm 10^{7} / \mathrm{ml}\right)$ and other assay conditions were constant. standard curve is shown in fig. 2 and the importance of adjusting this within narrow limits to achieve the maximum fall over the range of drug concentration measured is emphasized. In fig. 3 the standard curve is shown in four separate assays carried out over a period of two weeks. Good reproducibility is shown between separate assays. Serial dilution of test sera have shown that accurate readings are obtained at any point on the standard curve between 2 and $10 \mu \mathrm{g} / \mathrm{ml}$. The mean value ( \pm S.E. of mean) for a $60 \mu \mathrm{g} / \mathrm{ml}$ control serum obtained in 17 separate assays was $62.1 \pm 1 \cdot 7$. These results were adversely affected by two results of 81 and $75 \mu \mathrm{g} / \mathrm{ml}$ which were obtained from obviously abnormal curves which in normal laboratory practice would be discarded and the assay repeated. Exclusion of these two results gives a mean value of $59.9 \pm 0.8$ (co-efficient of variation $\pm 4.8 \%$ ).

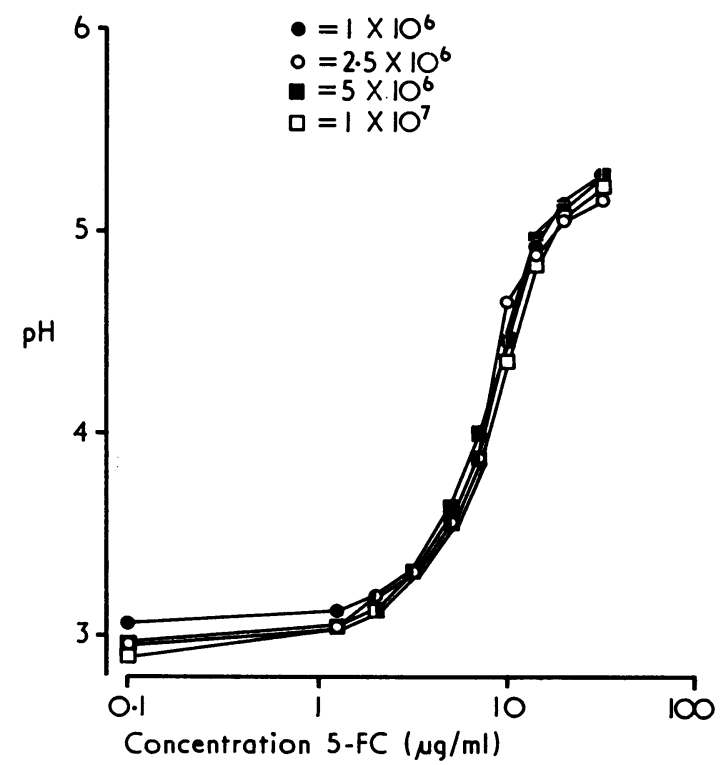

FIG. 3-Standard curves in four separate assays carried out over a period of two weeks showing good reproducibility under controlled conditions. (Interpretation of symbols as in fig. 1.)

\section{Discussion}

Since 5-FC is unpredictably neutralized by cytosine and peptones (Shadomy, 1969), it was necessary to use a synthetic culture medium to exclude these components despite the fact that such a medium does not provide optimal growth conditions for $C$. albicans. This, together with the longer generation time of $C$. albicans when compared with other organisms, introduced difficulties in achieving a rapid reproducible method. The assay was further complicated by the slowing of organism metabolism which occurs at low pH. To overcome these factors it has been necessary to define the conditions of the assay within fairly narrow limits.

Ideally a $\mathrm{pH}$ fall of about $3 \mathrm{pH}$ units for the zero-drug standard should be achieved to ensure a satisfactory curve over a sufficiently wide drug concentration range. The selected fall in $\mathrm{pH}$ should be monitored, preferably to $\pm 0.1 \mathrm{pH}$ units, from day to day if reproducible results are to be achieved. Variation in the initial concentration of the test organism and the $\mathrm{pH}$ at the start of the test should be kept within narrow limits as these factors have particular influence on the incubation time required to achieve an optimum pH fall.

Since small amounts of acid may produce a significant drop in $\mathrm{pH}$ in the virtually unbuffered culture medium, scrupulous cleanliness of the McCartney bottles is essential to eliminate 
extraneous sources of acid or alkali. This factor was initially one of the most difficult to control until a stringent washing technique was introduced. Use of a McCartney bottle for the $5-\mathrm{ml}$ test mixture ensures that sufficient surface area is available for aeration and accommodates gas released during incubation.

Since tests established that 5-FC could be autoclaved without affecting its antifungal activity, all standards, control sera, and test sera were autoclaved before incorporation in the assay mixture. This had the effect of driving off dissolved blood gases thus eliminating minor differences in starting $\mathrm{pH}$ which might occur from this cause. Furthermore, as protein is denatured the effect of specific or non-specific antibodies which may be present in test serum and which could interfere with growth of the organism and acid production is reduced.

Provided the conditions of the assay are observed, rapid reproducible estimation of $5-\mathrm{FC}$ in serum and urine can be obtained with an accuracy of about $\pm 5 \%$. The method is an improvement on the currently available assay techniques and should be applicable to the measurement of other antifungal agents.

D. J. S. and J. K. D. were supported by a grant from the Felton Bequest. Mrs. M. Henning and Mr. K. Wadsworth provided valuable technical help.

\section{References}

Faine, S., and Knight, D. C. (1968). Lancet, 2, 375.

Koechlin, B. A., Rubio, F., Palmer, S., Gabriel, T., and Duschinsky, R.

(1966). Biochemical Pharmacology, 15, 435.
Shadomy, S. (1969). Applied Microbiology, 17, 871.

Wade, D. N., and Sudlow, G. (1972). Australian and New Zealand fournal of Medicine, 2, 153.

\title{
Use of 5-Fluorocytosine in Patients with Impaired Renal Function
}

\author{
J. K. DAWBORN, M. D. PAGE, D. J. SCHIAVONE
}

British Medical fournal, 1973, 4, 382-384

\section{Summary}

The plasma level and elimination of 5-fluorocytosine (5-FC) was measured in normal subjects and patients with impaired renal function. Prolongation of the halflife of the drug in renal failure has been confirmed. Renal clearance of 5-FC was about $75 \%$ of the creatinine clearance and a corresponding modification of drug dosage should be made in patients with renal insufficiency.

\section{Introduction}

5-Fluorocytosine (5-FC) is an effective oral therapeutic agent for the treatment of fungal infections due to sensitive strains of Candida albicans, Cryptococcus neoformans, and Aspergillus fumigatus. The drug is not metabolized in man but is excreted almost entirely by the kidney (Koechlin et al., 1966; Wade and Sudlow, 1972). The recommended dose range in persons with normal kidney function is $0 \cdot 1-0 \cdot 2 \mathrm{~g} / \mathrm{kg} /$ day but this has not been firmly established and there is little information about blood and urine levels of the drug. The development of a rapid microbiological assay (Schiavone et al., 1973) has allowed us to make observations on the serum levels and urinary excretion of 5-FC in normal subjects and in patients with impaired renal function.

\section{Materials and Methods}

Twenty subjects were studied of whom five had normal renal

\footnotetext{
University of Melbourne, Austin Hospital, Heidelberg 3084, Victoria, Australia

J. K. DAWBORN, PH.D., F.R.A.C.P., Senior Renal Physician

M. D. PAGE, M.SC., Graduate Research Assistant, Department of

D. J. SCHIAVONE, M.B., F.R.C.P.A. Senior Lecturer in Medical Microbiology
}

function, four were anephric, and 11 had varying degrees of renal impairment (see table I). Each person was studied after an oral dose of $2 \mathrm{~g}$ 5-FC. Serum and urine 5-FC measurements were made as previously described (Schiavone et al., 1973). Serum levels of 5-FC were measured often over 12 hours in normal subjects and for up to 48 hours in patients with renal failure. In most subjects accurately timed urine collections were also obtained for calculation of 5-FC and creatinine clearances, and in four patients the removal of 5-FC was studied during haemodialysis.

The serum 5-FC levels (log scale) were plotted on semilogarithmic paper against time. After the first four hours the fall in serum 5-FC was about linear in all subjects and the biological half life $\left(t \frac{1}{2}\right)$ of the drug was calculated from the linear regression of $\log$ serum $5-\mathrm{FC}$ against time. The volume of distribution of the drug was calculated by extrapolating this curve to zero time and dividing the total dose by the derived value for the serum $5-\mathrm{FC}$ concentration at zero time. Clearances of 5-FC and creatinine were determined from a timed urine collection (usually the four- to eight-hour period after the dose) and the mean serum concentration for the collection period.

The assumption was made that the drug was not bound to protein (Wade and Sudlow, 1972). Clearance of creatinine and 5-FC by dialysis was calculated according to the formula:

$$
\text { dialysis clearance }=Q \quad \frac{(\mathrm{A}-\mathrm{V})}{\mathrm{A}}
$$

where $Q$ was the blood flow rate through the dialyser and $A$ and $\mathrm{V}$ were the serum levels of 5-FC or of creatinine respectively entering and leaving the dialyser. Creatinine was measured with a Technicon AutoAnalyzer. Statistical analyses were carried out with a Hewlett Packard computer and programs.

\section{Results}

These are summarized in table I. Serum 5-FC levels are compared in fig. 1 over 12 hours after an oral dose of $2 \mathrm{~g} \mathrm{5-FC} \mathrm{in}$ five normal subjects and in five patients with severe terminal renal failure (creatinine clearance $<3 \mathrm{ml} / \mathrm{min}$ ). When renal function was normal a mean peak level ( \pm S.E. of mean) of 